\title{
CONFORTO TÉRMICO EM TRABALHADORES DE AVIÁRIOS
}

\author{
Thermal comfort in aviary workers \\ Confort térmico en trabajadores de aviario
}

\begin{abstract}
Ana Ferreira*, Helder Simões**, João Paulo Figueiredo***, Susana Paixão****, Lúcia Simões Costa*****, Sílvia Seco******, António Loureiro*******
\end{abstract}

\section{RESUMO}

Enquadramento: podendo existir vulnerabilidade dos trabalhadores avícolas face às temperaturas do interior dos aviários em comparação com as do exterior é importante analisar a sua exposição ocupacional em termos de conforto térmico. Objetivos: avaliar o conforto térmico em trabalhadores do setor avícola no ambiente interior e exterior dos aviários e analisar a sua possível relação com a fase de desenvolvimento do frango. Metodologia: o estudo efetuado foi observacional, transversal, com uma amostra por conveniência de 6 trabalhadores de 8 aviários. A recolha de dados foi realizada através de um questionário dirigido a todos os trabalhadores seguida da medição dos valores de Predicted Mean Vote (PMV) e Predicted Percentage of Dissatisfied (PPD). Resultados: em aviários de frangos com 8 dias de idade verificou-se uma total concordância entre os valores de PMV e PPD, nos de 35 dias uma concordância significativa e nos de 85 dias uma considerável concordância. Conclusão: existe desconforto térmico nos trabalhadores avaliados, especialmente nos que trabalham em aviários para frangos com 8 e 35 dias de idade. 0 desconforto térmico foi pior nos aviários de frangos com 8 dias, revelando assim a relação entre o índice de conforto térmico e a fase de desenvolvimento do frango.

Palavras-Chaves: saúde ocupacional; exposição ocupacional; temperatura; avicultura

*PhD, Professora do Instituto Politécnico de Coimbra, Escola Superior de Tecnologia da Saúde de Coimbra, Departamento de Audiologia, Fisioterapia e Saúde Ambiental, Unid
Científico-Pedagógica de Saúde Ambiental https://orcid. org/0000-0003-3595-1554 - Contribuição no artigo: Study conception and design, Data collection, Data analysis and interpretation, Drafting of the article **MsC, Professor do Instituto Politécnico de Coimbra, Escola Superior de Tecnologia da Saúde de Coimbra, Departamento de Audiologia, Fisioterapia e Saúde Ambiental, Unidade Científico-Pedagógica de Saúde Ambiental http://orcid.org/0000-0002-3412-8462 - Contribuição no artigo: Study conception and design, Data collection, Data analysis and interpretation, Drafting of the article

*** PhD, Professor do Instituto Politécnico de Coimbra, Escola Superior de Tecnologia da Saúde de Coimbra, Pedagógica de Ciências Médicas, Sociais e Humanas Pedagogica de Clências Médicas, Sociais e Humanas -
https://orcid.org/0000-0002-9829-1592 - Contribuiçăo no https://orcid.org/0000-0002-9829-1592 - Contribuição no artigo: Study conception and design, Data analysis and interpretation, Drafting of the article
${ }_{*}^{* * * *}$ PhD, Professora do Instituto Politécnico de Coimbra, Escola Superior de Tecnologia da Saúde de Coimbra, Departamento de Audiologia, Fisioterapia e Saúde Ambiental, Unidade Científico-Pedagógica de Saúde Ambiental - https://orcid.org/0000-0002-4548-1894 Contribuição no artigo: Critical revision of the article ***** PhD, Professora do Instituto Politécnico de Coimbra, Escola Superior de Tecnologia da Saúde de Coimbra, Pepartamento de Ciencias Médicas, Sociais e Humanas Pedagogica de Clências Medicas, Sociais e Humanas artigo: Data analysis and interpretation, Critical revision of the article

${ }_{* * * * * *} \mathrm{MsC}$, Professora do Instituto Politécnico de Coimbra, Serviço de Saúde Ocupacional e Ambiental https://orcid.org/0000-0002-3234-8058 Contribuição no artigo: Critical revision of the article

******** MsC, Professor do Instituto Politécnico de Coimbra, Serviço de Saúde Ocupacional e Ambiental https://orcid.org/0000-0002-3261-7924 - Contribuição no artigo: Study conception and design, Study conception and design, Drafting of the article

\section{Como referenciar:}

Ferreira, A., Simões, H., Figueiredo, J.P., Paixão, S., Costa, L., Seco, S., \& Loureiro, A., (2021). Conforto térmico em trabalhadores de aviários. Revista de Investigação \& Inovação em Saúde. 4(1), 47-59 https://doi.org/10.37914 riis.v4i1.145

Recebido para publicação em: 04/05/2021 Aceite para publicação:22/06/2021

\section{ABSTRACT}

Background: as there may be vulnerability of poultry workers to the temperatures inside the aviaries compared to those outside, it is important to analyze their occupational exposure in terms of thermal comfort. Objectives: evaluate the thermal comfort in poultry sector workers in indoor and outdoor environments and analyze its possible relationship with the chicken developmental stage. Methodology: the study carried out was observational, cross-sectional, with a convenience sample of 6 workers from 8 aviaries. Data collection was carried out through a questionnaire addressed to all workers followed by the measurement of Predicted Mean Vote (PMV) and Predicted Percentage of Dissatisfied (PPD). Results: in 8-day-old chicken aviaries there was a complete agreement between the values of PMV and PPD, in the 35-day-old aviaries a significant agreement and in the 85-day-old a considerable agreement. Conclusion: there is thermal discomfort in the assessed workers, especially in those who work in aviaries for chickens with 8 and 35 days of age. Thermal discomfort was worse in 8-day-old chicken aviaries, thus revealing the relationship between the thermal comfort index and the chicken development stage. Keywords: occupational health; occupational exposure; temperature; poultry farming

\section{RESUMEN}

Marco contextual: como puede haber vulnerabilidad de los trabajadores avícolas a las temperaturas dentro de los aviarios en comparación con las del exterior, es importante analizar su exposición ocupacional en relación al confort térmico. Objetivos: evaluar el confort térmico en trabajadores del sector avícola en ambientes interiores y exteriores y analizar su posible relación con la etapa de desarrollo del pollo. Metodología: el estudio realizado fue observacional, transversal, con una muestra de conveniencia de 6 trabajadores de 8 aviarios. La recogida de datos se realizó mediante un cuestionario dirigido a todos los trabajadores seguido de la medición de los valores de Predicted Mean Vote (PMV) y Predicted Percentage of Dissatisfied (PPD). Resultados: en aviarios de pollos de 8 días hubo una concordancia total entre los valores de PMV y PPD, en 35 días una concordancia significativa y en 85 días una concordancia considerable. Conclusión: existe malestar térmico en los trabajadores evaluados, especialmente aquellos que laboran en aviarios para pollos con 8 y 35 días de edad. El malestar térmico fue peor en los aviarios de pollos de 8 días, revelando así la relación entre el índice de confort térmico y la etapa de desarrollo del pollo.

Palabras Claves: salud ocupacional; exposición ocupacional; temperatura; avicultura 


\section{INTRODUÇÃO}

O período de inverno comporta, sempre, preocupações acrescidas para os produtores de frangos em regiões mais frias, sendo necessário estar mais atento ao interior do aviário, em especial no que diz respeito à temperatura (Fernandes \& Furlaneto, 2004). No entanto, conhecidas as fragilidades das aves e as temperaturas ideais para o seu desenvolvimento, tendo em conta a fase de gestação em que se encontram, há também que investigar a vulnerabilidade dos trabalhadores, quanto às temperaturas do interior dos aviários, em comparação com as do exterior, principalmente durante esse período do ano (Silva \& Almeida, 2010; Oliveira, 2008). A promoção da saúde e segurança destes trabalhadores deverá ser, também, uma prioridade, pelo que é importante investigar a sua exposição ocupacional em termos de conforto térmico.

Assim, este estudo teve como objetivos avaliar conforto térmico em trabalhadores do setor avícola no ambiente interior e exterior dos aviários e analisar a sua possível relação com a fase de desenvolvimento do frango.

\section{ENQUADRAMENTO/FUNDAMENTAÇÃO TEÓRICA}

A publicação de normalização e códigos de boas práticas relacionadas com o ambiente térmico, pela International Organization for Standartization (ISO) e pela American Society for Heating, refrigeration and Air-Conditioning Engineers (ASHRAE) veio reforçar a importância do estudo desta temática e a obrigatoriedade de a legislar de forma a salvaguardar a saúde do trabalhador (Talaia, 2013).

Conforto térmico é definido pela norma ISO 7730/05 como "aquela condição de mente na qual é expressa satisfação com o ambiente térmico". A primeira conclusão a que se chega, partindo desta afirmação, é que este é um conceito subjetivo, que varia de indivíduo para indivíduo. Assim, é necessário conjugar inúmeras variáveis de modo a definir o conforto térmico associado a um determinado ambiente (Silva, 2020; Oliveira, 2008). Segundo Fanger (1970), neutralidade térmica é a condição que se pretende atingir, na qual uma pessoa não prefira nem mais calor nem mais frio, em relação ao ambiente térmico em que se encontra (Vergara, 2001; Fanger, 1970).

O conforto térmico depende de fatores que interferem no trabalho do sistema termorregulador humano, são eles: taxa de metabolismo, vestuário, temperatura radiante, humidade relativa, temperatura do ar e velocidade do ar. $\mathrm{O}$ efeito combinado de todos esses fatores, determinará a sensação de conforto ou desconforto térmico embora, por motivo de classificação, os dois primeiros fatores sejam chamados de variáveis pessoais/individuais e os quatro últimos de variáveis ambientais (Ndembo, 2018; Gonçalves, 2017).

A ISO 7730/05 aplica a avaliação do conforto térmico a ambientes térmicos moderados, apresentando métodos para prever a sensação térmica geral, bem como o grau de desconforto (insatisfação térmica) das pessoas expostas a estes ambientes térmicos. Particularizando, permite a determinação e interpretação do conforto térmico, através do cálculo do PMV e de PPD (Gonçalves, 2017; Oliveira, 2008; ISO 7730:2005, 2005).

Estudos revelam que na presença de um posto de trabalho termicamente desconfortável, manifestarse-ão nos trabalhadores, consequências como indisposição e fadiga, diminuindo a eficiência e 
aumentando os riscos de acidente (Painçal, Nunes, \& Fernandes, 2018; Minette, Silva, Souza, \& Silva, 2007). Uma das causas possíveis reside nas alterações de temperatura, as quais acarretam um dispêndio adicional de esforço biológico para recuperação da condição homeotérmica, acentuando-se a sensação de desconforto e fadiga, com consequências negativas para a saúde e rendimento dos seus ocupantes (Almeida, 2010). A organização assume um papel preponderante na implementação de pausas laborais para os funcionários, a fim de minimizar os efeitos de fadiga térmica, frequentemente detetados nas avaliações de conforto térmico (Gonçalves, 2017; Silva, 2013).

É ainda de salientar a Lei n. o 3/2014, de 28 de janeiro, que regulamenta o regime jurídico da promoção da segurança e saúde no trabalho, comunicando as obrigações gerais do empregador, o qual é obrigado a assegurar ao trabalhador, condições de segurança e saúde em todos os aspetos do seu trabalho, atendendo aos princípios gerais de prevenção: "assegurar, nos locais de trabalho, que as exposições a agentes físicos e biológicos e aos fatores de risco psicossociais não constituem risco para a segurança e saúde do trabalhador (Lei n. 3, 2014; Portaria n.ㅇ 702/80, 1980).

Já o Regulamento Geral de Segurança e Higiene do Trabalho nos Estabelecimentos Industriais, Portaria no 53, 1971, alterada pela Portaria n.o 702/80, de 22 de setembro, estabelece no artigo $24^{\circ}$, quanto à temperatura e humidade que: "as condições de temperatura e humidade dos locais de trabalho devem ser mantidas dentro de limites convenientes para evitar prejuízos à saúde dos trabalhadores" (Portaria n.o 702/80, de 22 de setembro, 1980).
Não sendo possível conceber um ambiente comum, em que a totalidade dos seus ocupantes se sinta termicamente confortável, procuram-se criar condições para que isso mesmo se aplique à correspondente maioria. Sendo esta uma área em constante desenvolvimento, têm vindo a surgir softwares que permitem determinar facilmente os índices PMV e PPD relativos ao nível de conforto térmico de um dado ambiente.

O PMV corresponde a uma estimativa da votação de um determinado número de pessoas, relativamente à sua sensação térmica do ambiente circundante. Este índice pode ser determinado a partir do metabolismo, do vestuário e dos parâmetros ambientais (temperatura do ar, temperatura radiante, velocidade do ar e humidade relativa). $O$ índice PPD estabelece uma previsão quantitativa do número de pessoas insatisfeitas (Gonçalves, 2017; Miguel, 2014).

\section{METODOLOGIA}

O estudo efetuado foi observacional e analítico, nível III (correlacional), transversal e com um tipo de amostragem não probabilístico de conveniência. A amostra foi constituída por 6 trabalhadores de 8 aviários de 2 empresas do distrito da Guarda. Dos aviários, 4 eram de frangos com 8 dias de idade, 1 de frangos com 35 dias e 3 de frangos com 85 dias de idade.

A recolha de dados decorreu em dois momentos, sendo o primeiro a aplicação de um questionário dirigido a todos os trabalhadores e o segundo a medição dos parâmetros de conforto térmico a que os avicultores se encontravam expostos para se determinarem os valores de Predicted Mean Vote (PMV) e Predicted Percentage of Dissatisfied (PPD). 
Através do questionário pretendeu-se determinar o tipo de vestuário utlizado pelos trabalhadores durante a realização das suas tarefas nos aviários; compreender a perceção dos trabalhadores relativamente ao tipo de atividade desempenhada; quais os sinais/sintomas/doenças que os trabalhadores experimentavam e se os mesmos tendem a agravar nas estações de verão ou de inverno.

A avaliação do conforto térmico, foi realizada através do analisador térmico de microclimas Delta Ohm HD 32.1, AM510-1c12 2,940He SA, devidamente certificado e calibrado. Os parâmetros ambientais avaliados, relativamente ao conforto térmico foram: velocidade do ar (Var), humidade relativa $(\mathrm{Hr})$, temperatura do ar (Ta) e temperatura radiante (Tr). Foram realizadas várias medições com uma duração 15 minutos cada, com amostragens de 15 em 15 segundos. As medições foram realizadas a aproximadamente $1,50 \mathrm{~m}$ de altura, dado esta ser a altura coincidente, com a zona de maior concentração de calor humano, a zona do peito. É de salientar a necessidade de aclimatar as sondas do equipamento, antes da realização de qualquer medição, para que não haja qualquer tipo de influência e as sondas se ajustem adequadamente às caraterísticas do local de medição. Antes de qualquer medição, foi efetuado um processo de aclimatização dos edifícios de 30 minutos. A medição das variáveis ambientais foi realizada segundo procedimentos e métodos de medição apresentados na norma ISO 7730/05.

De acordo com o layout dos aviários, os pontos de medição foram considerados, de forma a tornar o local o mais representativo possível. O número de medições dependeu das dimensões de cada aviário, no entanto a cada $50 \mathrm{~m}^{2}$ foi realizada uma avaliação. No exterior dos aviários destinados a frangos com 35 dias de idade, foram realizadas quatro medições, e nos restantes efetuaram-se duas medições no exterior.

Após a recolha de dados, os mesmos foram tratados utilizando o sofware de conforto térmico DeltaLog 10 versão 0.1.5.29 e ainda o software estatístico IBM SPSS versão 27.0 .

O tipo de vestuário utilizado pelos trabalhadores durante a realização das suas tarefas e a sua perceção relativa ao tipo de atividade desempenhada são dois fatores essenciais na utilização do software DeltaLog 10, pelo que o vestuário é um fator individual imprescindível à avaliação do conforto térmico e requerido pelo software, dado influenciar o algoritmo chave ao cálculo do PMV e PPD, através da adição de um valor com a unidade de medida clo, o qual corresponderá à resistência térmica. É, igualmente, importante considerar o tipo de atividade realizada pelo trabalhador, outro dos fatores individuais que resultará no valor da sua taxa metabólica, valor este capaz de influenciar significativamente os resultados. Assim, o cálculo dos valores de PMV e PPD, baseia-se na combinação entre os parâmetros ambientais e as características individuais (vestuário e taxa metabólica). Atendendo ao facto de a ISO 7730/05 ser demasiadamente generalista na atribuição das taxas metabólicas quanto aos vários tipos de atividades profissionais que menciona e, visto que os trabalhadores em questão executam muito mais que uma tarefa, considerou-se sensata a atribuição de taxa metabólica moderada de valor (Hudie, 2016). Trata-se de uma função não legalmente definida, e tanto pelas respostas obtidas no questionário, como pela 
variedade de funções desempenhadas, pode-se concluir que se trata efetivamente de uma profissão com uma taxa metabólica moderada.

O índice PMV-PPD é recomendado pela ISO 7730/05 para a caraterização de ambientes confortáveis. Os limites a considerar para os valores de PMV e PPD são: $-0,5<\mathrm{PMV}<+0,5$ e PPD $<30 \%$. Quando ambas as condições se verificarem, estamos perante um local de trabalhado termicamente confortável, ou viceversa (Silva, 2013; Almeida, 2010). Verificados os valores de PMV e PPD, é efetuada a análise dos

\section{Tabela 1}

Níveis de concordância para o teste Kappa de Cohen

\begin{tabular}{cc}
\hline \hline$<0$ & Não há concordância \\
\hline$[0,00-0,20]$ & Desprezável concordância \\
\hline$[0,21-0,40]$ & Baixa concordância \\
\hline$[0,41-0,60]$ & Moderada concordância \\
\hline$[0,61-0,80]$ & Boa concordância \\
\hline$\geq 0,81$ & Concordância quase perfeita \\
\hline \hline
\end{tabular}

\section{RESULTADOS}

Através do questionário, observou-se que a idade média dos 6 trabalhadores ( 4 do sexo masculino e 2 do sexo feminino) foi de $45,17 \pm 11,374$ anos, com uma média de 10,50 \pm 4,324 anos de trabalho nas instalações. 83,3\% dos trabalhadores exerciam as suas funções durante 8 horas/dia, sendo que apenas 1 trabalhava 10 horas/dia. Para a realização das suas tarefas, os trabalhadores encontravam-se distribuídos de forma equitativa pelo interior e exterior dos aviários, sendo que a maioria desenvolvia as suas tarefas na posição de pé. Os trabalhadores eram polivalentes, pois realizavam qualquer tarefa mesmos, consoante estes se encontrem conformes ou não, com o valor legislado. Relativamente à inferência estatística foram aplicados o teste de hipótese Kappa de Cohen, com a finalidade de verificar a existência de concordância entre os indicadores em estudo. A interpretação do teste estatístico foi realizada com base num nível de significância de $p=0,05$ com um intervalo de confiança de 95\%. Quando realizado o teste de Kappa de Cohen, os valores de kappa obtidos, foram analisados com base no nível de concordância, que lhe é correspondente, como indicado na tabela 1. necessária num aviário, sendo elas: preparação do pavilhão, receção dos pintos, recria e crescimento dos frangos, saída dos frangos para abate, remoção de equipamentos e resíduos e lavagem e desinfeção das instalações e equipamentos. Verificou-se, ainda, que a exposição dos trabalhadores no interior dos aviários não ocorreu de forma continuada, pois como efetuavam várias tarefas, passavam, também, bastante tempo no seu exterior. Na figura 1, são apresentados os sinais/ sintomas/doenças que os trabalhadores indicaram sentir, com frequência, no seu local de trabalho. 


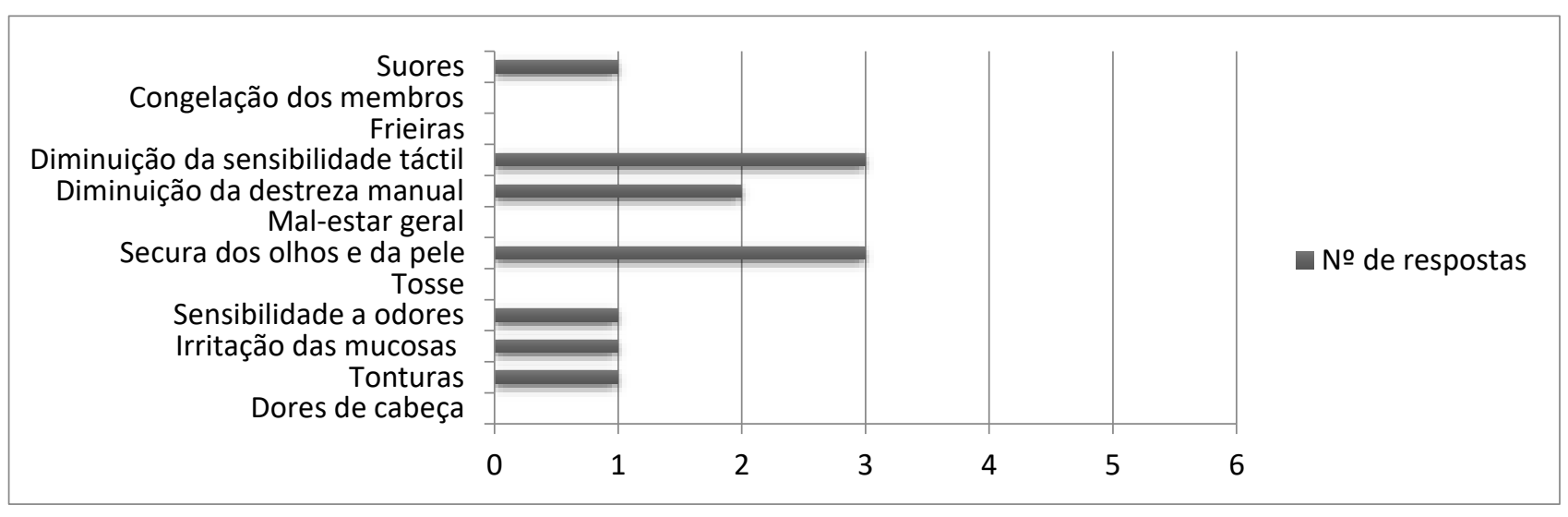

Figura 1

Sinais/sintomas/doenças reportados pelos trabalhadores

Do total de trabalhadores inquiridos, a maioria referiu que os sintomas indicados se tendiam a agravar na estação de inverno, sendo que 4 dos 6 trabalhadores, referiram não deixar de sentir os sinais/sintomas/doenças quando estavam no exterior das instalações. Quanto ao isolamento térmico, o vestuário utilizado pela grande maioria dos trabalhadores, resumia-se à utilização de camisa de manga comprida, calças e botas. Para além da camisa, metade dos trabalhadores não utilizava mais nenhum tipo de vestuário no tronco, e os restantes usavam camisola, casaco ou ambos.

De seguida, procurou-se avaliar o grau de conforto/desconforto térmico, ao nível dos trabalhadores, através da concordância dos valores de PMV e PPD, relativos aos aviários destinados às diferentes fases de desenvolvimento do frango, atendendo ao local da medição. Na Tabela 2, está a análise da concordância entre os valores de PMV e PPD em aviários de frangos com 8 dias de idade.

\section{Tabela 2}

Concordância entre valores de PMV e PPD em aviários de frangos com 8 dias de idade.

\begin{tabular}{|c|c|c|c|c|c|c|}
\hline & \multicolumn{6}{|c|}{ PPD - 8 dias } \\
\hline & & & Conforto térmico (\%) & Desconforto térmico (\%) & Total (\%) & Teste \\
\hline \multirow{6}{*}{$\begin{array}{l}\tilde{n} \\
\frac{\pi}{0} \\
\infty \\
1 \\
\sum_{a}\end{array}$} & \multirow{3}{*}{ হ̄ } & Conforto térmico & $15(100,0 \%)$ & 0 & $15(18,8 \%)$ & \multirow{3}{*}{$\begin{array}{l}k=0,671 \\
p<0,001\end{array}$} \\
\hline & & Desconforto térmico & $10(15,4 \%)$ & $55(84,6 \%)$ & $65(81,3 \%)$ & \\
\hline & & Total & $25(31,3 \%)$ & $55(68,8 \%)$ & $80(100,0 \%)$ & \\
\hline & \multirow{3}{*}{ 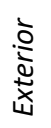 } & Conforto térmico & $15(100,0 \%)$ & 0 & $15(37,5 \%)$ & \multirow{3}{*}{$\begin{array}{l}k=0,529 \\
p<0,001\end{array}$} \\
\hline & & Desconforto térmico & $10(40,0 \%)$ & $15(60,0 \%)$ & $25(62,5 \%)$ & \\
\hline & & Total & $25(62,5 \%)$ & $15(37,5 \%)$ & $40(100,0 \%)$ & \\
\hline
\end{tabular}

Teste de Kappa de Cohen

Observou-se uma boa concordância de resultados $(67,1 \%)$, no que diz respeito à avaliação de PMV 8 dias com PPD 8 dias, de uma forma geral, em que das 15 avaliações identificadas por PMV como confortáveis, foram igualmente classificadas ao nível do parâmetro de PPD. A concordância ao nível do desconforto 
térmico foi de $84,6 \%$. Particularizando, no interior de um aviário para frangos com 8 dias de idade, verificouse uma significativa concordância, o que se resume numa sintonia total dos valores de PMV e PPD, isto é, o PMV e PPD revelaram um ambiente térmico desconfortável ao trabalhador.

Relativamente ao exterior, a concordância de resultados de PMV e PPD 8 dias, verificou-se ser de $52,9 \%$, ligeiramente inferior à "avaliação geral" e bastante inferior à avaliação das medições efetuadas em ambiente interior. Das 15 medições classificadas como conformes, ao nível da sensação térmica do trabalhador, ou seja, ao nível do PMV, também foram assim avaliadas pelo PPD. No que se refere aos valores atribuídos por PMV, como desfavoráveis ao trabalhador, verificou-se que, 25 das medições efetuadas no exterior destes aviários não proporcionam uma sensação térmica agradável ao trabalhador. Contudo, dessas medições, 15 foram também assim classificadas no que diz respeito ao parâmetro PPD.

Na Tabela 3, apresenta-se a análise da concordância entre valores de PMV e PPD em aviários de frangos com 35 dias de idade.

Tabela 3

Concordância entre valores de PMV e PPD em aviários de frangos com35 dias de idade

\begin{tabular}{|c|c|c|c|c|c|c|}
\hline & \multicolumn{6}{|c|}{ PPD - 35 dias } \\
\hline & & & Conforto térmico (\%) & Desconforto térmico (\%) & Total (\%) & Teste \\
\hline \multirow{9}{*}{$\begin{array}{l}\frac{n}{0} \\
\frac{0}{0} \\
n \\
m \\
1 \\
\geq \\
\sum_{0}\end{array}$} & \multirow{3}{*}{$\begin{array}{l}\overline{0} \\
\text { ৫ั }\end{array}$} & Conforto térmico & $7(100,0 \%)$ & 0 & $7(9,3 \%)$ & \multirow{3}{*}{$\begin{array}{l}k=0,583 \\
p<0,001\end{array}$} \\
\hline & & Desconforto térmico & $8(11,8 \%)$ & $60(88,2 \%)$ & $68(90,7 \%)$ & \\
\hline & & Total & $15(20,0 \%)$ & $60(80,0 \%)$ & $75(100,0 \%)$ & \\
\hline & \multirow{3}{*}{ 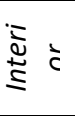 } & Conforto térmico & 0 & 0 & 0 & \multirow{3}{*}{-} \\
\hline & & Desconforto térmico & $4(7,3 \%)$ & $51(92,7 \%)$ & $55(100,0 \%)$ & \\
\hline & & Total & $4(7,3 \%)$ & $51(92,7 \%)$ & $55(100,0 \%)$ & \\
\hline & \multirow{3}{*}{ 六 } & Conforto térmico & $7(100,0 \%)$ & 0 & $7(35,0 \%)$ & \multirow{3}{*}{$\begin{array}{l}k=0,612 \\
p=0,003\end{array}$} \\
\hline & & Desconforto térmico & $4(30,8 \%)$ & $9(69,2 \%)$ & $13(65,0 \%)$ & \\
\hline & & Total & $11(55,0 \%)$ & $9(45,0 \%)$ & $20(100,0 \%)$ & \\
\hline
\end{tabular}

Teste de Kappa de Cohen

De uma forma geral, existiu uma boa concordância $(58,3 \%)$ o que se deve ao facto de, 7 das medições consideradas adequadas ao nível do PMV, também foram avaliadas pelo parâmetro PPD. Revelou-se, portanto, uma sintonia de valores entre os dois parâmetros em avaliação (PMV e PPD), ao nível do conforto térmico. $88,2 \%$ das medições, sendo que destas 68 medições foram consideradas não conformes pelo PMV, 8 foram avaliadas como confortáveis ao trabalhador, ao nível do PPD.

No que diz respeito às medições realizadas no interior dos aviários destinados a frangos com a idade de 35 dias, não houve qualquer medição caraterizada como termicamente confortável, para ambos os parâmetros. É ainda de salientar, que relativamente ao parâmetro PMV, todas as medições foram avaliadas como desconfortáveis ao trabalhador, naquele ambiente. Quanto ao PPD, das 55 medições realizadas no interior destes aviários, 92,7\% revelaram um ambiente desconfortável para o trabalhador.

Perante os resultados dos parâmetros PMV e PPD no exterior dos aviários de frangos de 35 dias de idade, observou-se uma boa concordância dos mesmos, concordância esta de 61,2\%. Das 20 medições 
efetuadas no exterior destes aviários, as que foram classificadas como termicamente confortáveis para os trabalhadores ao nível do PMV, também o foram pelo PPD, perfazendo $35 \%$ do total de medições. Das medições classificadas como desconfortáveis pelo PMV, 30,8\% foram avaliadas como confortáveis ao nível do parâmetro PPD, pelo que as restantes, ou seja, 69,2\% apresentaram sintonia entre os parâmetros.

Por último, a Tabela 4 demonstra a concordância entre os valores de PMV e PPD em aviários de frangos com 85 dias de idade.

Tabela 4

Concordância entre valores de PMV e PPD em aviários de frangos com 85 dias de idade

\begin{tabular}{|c|c|c|c|c|c|c|}
\hline & \multicolumn{6}{|c|}{ PPD - 85 dias } \\
\hline & & & Conforto térmico (\%) & Desconforto térmico (\%) & Total (\%) & Teste \\
\hline \multirow{9}{*}{$\begin{array}{l}\mathscr{n} \\
\frac{0}{0} \\
\text { Ln } \\
\infty \\
1 \\
\sum_{a}\end{array}$} & \multirow{3}{*}{ হু } & Conforto térmico & $21(100,0 \%)$ & 0 & $21(35,0 \%)$ & \multirow{3}{*}{$\begin{array}{l}k=0,351 \\
p<0,001\end{array}$} \\
\hline & & Desconforto térmico & $22(56,4 \%)$ & $17(43,6 \%)$ & $39(65,0 \%)$ & \\
\hline & & Total & $43(71,7 \%)$ & $17(28,3 \%)$ & $60(100,0 \%)$ & \\
\hline & \multirow{3}{*}{$\stackrel{0}{\frac{0}{2}}+$} & Conforto térmico & $15(100,0 \%)$ & 0 & $15(50,0 \%)$ & \multirow{3}{*}{$\begin{array}{l}k=0,067 \\
p=0,309\end{array}$} \\
\hline & & Desconforto térmico & $14(93,3 \%)$ & $1(6,7 \%)$ & $15(50,0 \%)$ & \\
\hline & & Total & $29(96,7 \%)$ & $1(3,3 \%)$ & $30(100,0 \%)$ & \\
\hline & \multirow{3}{*}{ 离 c } & Conforto térmico & $6(100,0 \%)$ & 0 & $6(20,0 \%)$ & \multirow{3}{*}{$\begin{array}{l}k=0,444 \\
p=0,003\end{array}$} \\
\hline & & Desconforto térmico & $8(33,3 \%)$ & $16(66,7 \%)$ & $24(80,0 \%)$ & \\
\hline & & Total & $14(46,7 \%)$ & $16(53,3 \%)$ & $30(100,0 \%)$ & \\
\hline
\end{tabular}

Teste de Kappa de Cohen

Observou-se uma baixa concordância $(35,0 \%)$ no que se refere à avaliação de PMV 85 dias com PPD 85 dias, de uma forma geral. Todas as medições avaliadas como confortáveis no que toca ao PMV, foram igualmente classificadas pelo PPD. Contudo, nas medições consideradas desconfortáveis relativamente ao seu PMV, 56,4\% revelaram satisfação por parte dos trabalhadores relativamente ao seu ambiente térmico, isto é, o PPD revelou valores adequados, estando em sintonia apenas os restantes $43,6 \%$, nos quais PMV 85 dias e PPD 85 dias coincidiram.

Do total de medições realizadas no interior destes aviários, 50\% corresponderam a medições cuja análise dos parâmetros PMV e PPD coincidiram, pelo que ambos revelaram conforto térmico para o trabalhador. Das restantes medições, 93,3\% revelaram uma inadequada sensação térmica por parte do trabalhador
(PMV), mas simultaneamente que menos de $30 \%$ dos trabalhadores se encontravam insatisfeitos com o ambiente térmico a que se encontravam expostos, no local da medição (PPD). Apenas 1 das medições avaliadas como não conformes relativamente ao seu PMV, também assim foram classificadas pelo parâmetro PPD, neste ambiente interior.

Relativamente aos resultados da avaliação de PMV 85 dias com PPD 85 dias, no âmbito das medições efetuadas no exterior dos aviários destinados aos frangos nesta fase evolutiva, verificou-se uma concordância estatisticamente significativa. Das 30 medições realizadas no exterior destes aviários, constatou-se a concordância de resultados a nível de conforto térmico, pelo que das 6 medições conformes pelo seu PMV, também se encontravam em concordância pelo parâmetro PPD. Das medições 
realizadas em função do ambiente exterior, verificouse uma concordância de resultados em termos de desconforto térmico de $66,7 \%$, isto é, das 24 medições que reportavam uma incorreta sensação térmica por parte do trabalhador, ou seja, a não conformidade relativamente ao PMV, 16 coincidiram com o conforto térmico, igualmente atribuído pelo PPD.

\section{DISCUSSÃO}

Perante as informações recolhidas através do questionário, constatou-se que apesar de 5 dos trabalhadores exercerem as suas tarefas laborais durante 8 horas/dia, e 1 deles durante 10, os trabalhadores não se encontravam expostos de forma continuada ao ambiente do interior dos aviários, uma vez que passavam algum tempo a efetuar tarefas no exterior, o que se justificou pela diversidade de tarefas realizadas pelos mesmos. $\mathrm{O}$ trabalhador de aviário tem uma rotina de tarefas diversificada, não permanecendo no ambiente interior do aviário durante toda a jornada de trabalho (Coelho, 2018; Fernandes \& Furlaneto, 2004). Relativamente ao vestuário dos trabalhadores, este não tem em atenção a diferença de temperaturas sentidas entre o interior $\mathrm{e}$ o exterior dos aviários, não sendo diferenciado. Dado que durante a estação de inverno, as temperaturas nesta zona do país são muito baixas, e estando expostos também às do interior dos aviários, que são temperaturas mais elevadas, existirá desconforto térmico capaz de trazer consequências aos trabalhadores. De forma a adequar o parâmetro do vestuário, seria apropriado a alteração do mesmo ao mudar de ambiente, ou modificações ao nível estrutural, com o intuito de diminuir o choque térmico sentido, e os trabalhadores não serem expostos a uma alteração brusca de temperaturas, consoante trabalhem em ambiente interior ou exterior.

Os sinais/sintomas/doenças sentidos frequentemente pelos trabalhadores, poderão ser causados pelo desconforto térmico a que estes estão sujeitos aquando da sua exposição no interior ou exterior dos aviários, assumidos na sua maioria, como um local de trabalho termicamente desconfortável, quer por temperaturas baixas ou altas. Os sintomas de exposição a ambientes térmicos quentes podem ser: aumento da temperatura superficial da pele, aumento da temperatura interna, sudação, mal-estar generalizado, tonturas e desmaios, esgotamento e até a morte (Sousa, et al., 2005). A destreza manual pode ainda ser uma consequência direta, da perda de água excessiva pelo organismo do trabalhador, ou seja, quando expostos a ambientes quentes, ocorre desidratação, verificando-se uma taxa de sudação muito elevada (Sá, 1999). A secura dos olhos e da pele, advém do facto de o interior dos aviários, por vezes, se tornar como que um edifício doente, por exemplo no caso dos aviários para frangos com 8 dias de idade, cuja ventilação é inexistente e a temperatura no interior é alta comparativamente à que se sente no exterior durante a estação de inverno (Paulino, Oliveira, Grieser, \& Toledo, 2019; Sanguessuga, 2012). Contudo, a secura da pele, pode ser igualmente causada pela exposição a ambientes frios, como acontece aquando da realização das tarefas no exterior dos aviários, nesta estação do ano, quando frequentemente se fazem sentir temperaturas negativas (Paulino, Oliveira, Grieser, \& Toledo, 2019; Sanguessuga, 2012). É de referir, de forma particular, a exposição das partes 
descobertas, como é o caso das mãos e da face (e ainda dos braços, no caso de um dos trabalhadores, que referiu utilizar camisola de manga curta no seu vestuário laboral), que origina um aumento da pressão arterial e uma diminuição ou aumento da frequência cardíaca, sendo que estes dois efeitos, se traduzem num acréscimo do trabalho do coração (Miguel, 2014). Analisada a concordância entre os valores de PMV e PPD em aviários de frangos com 8 dias de idade, existe uma total sintonia em termos de desconforto térmico para o trabalhador, no interior dos aviários, neste período de gestação. O interior dos aviários de frangos neste nível de desenvolvimento será, provavelmente, das situações mais críticas, em termos de exposição ocupacional ao calor. Tal justifica-se, pelas altas temperaturas que se fazem sentir e falta de ventilação, pois nesta idade, as janelas e aberturas para o exterior, estão permanentemente fechadas, o que torna o ambiente muito "pesado". Acresce o facto de ser inverno, numa zona fria do país, cuja transição do exterior para o interior dos aviários, sem qualquer tipo de cuidado acrescido, certamente resulta em choque térmico para os trabalhadores (Coelho, 2018).

Relativamente à avaliação dos parâmetros PMV 35 dias com PPD 35 dias, verificou-se uma significativa concordância de resultados. Não houve qualquer medição caraterizada como confortavelmente térmica no interior destes aviários, o que revela verdadeiramente o desconforto térmico que se faz sentir. Ainda que mais baixas, as temperaturas nos aviários para frangos nesta fase de desenvolvimento, são ainda desconfortáveis ao trabalhador, enfatizando o facto de a única ventilação existente se resumir à abertura parcial de algumas das janelas, pelo que as gateiras destes aviários se encontravam fechadas (Coelho, 2018).

No que concerne à avaliação de PMV 85 dias com PPD 85 dias, a concordância de resultados diminuiu - de uma significativa concordância de $67,1 \%$ nos aviários para frangos com 8 dias de idade, para uma considerável concordância de 35,1\%, quanto à "avaliação geral" dos mesmos. No ambiente interior destes aviários, 50\% das medições revelaram conforto térmico para o trabalhador e consequentemente, os outros $50 \%$, revelaram desconforto térmico. É de assinalar a abertura completa das janelas e da maior parte das gateiras, o que durante o inverno não será o mais indicado para o trabalhador, pelas bruscas correntes de ar que se fazem sentir (Coelho, 2018).

Analisando o desconforto térmico, como forma de atuar ao nível da prevenção do mesmo, e da redução ou até mesmo eliminação de doenças profissionais, aquando da sua exposição no exterior, recomenda-se o uso de vestuário exterior impermeável e corta-vento, com capuz (pelo menos 50\% do calor do corpo, é perdido através da cabeça e do pescoço), gorro protetor de face, camisa de manga comprida e gola alta, de forma a proteger a maior área de pele possível, meias de lã, calças térmicas ou com forro especial, botas isolantes ou de couro e luvas anti frio.

Já no interior dos aviários, torna-se imprescindível que seja usado vestuário com um elevado peso por superfície, e que pelo menos $90 \%$ da superfície corporal esteja coberta, dado que o vestuário irá manter, ao longo do tempo de exposição, o equilíbrio das trocas de calor-ambiente, isto para que a temperatura superficial do corpo humano, não sofra qualquer sobreaquecimento ou sobrearrefecimento 
(Miguel, 2014). No entanto, no ambiente interior dos aviários, as medidas corretivas mais eficazes serão, sem dúvida, a implementação de ventilação e de uma zona para recuperação térmica, fresca, com maior ventilação, para que os trabalhadores se climatizem gradualmente à mudança de temperaturas, durante $o$ inverno. Ainda no que diz respeito à ventilação, no caso dos aviários para frangos de 8 e 85 dias, considerando o pé-direito, é de ter em conta que um telhado com grande inclinação, motiva maior velocidade do ar sobre a cumeeira e, como consequência, ocorre uma pressão negativa mais acentuada, sendo o ar mais rapidamente direcionado para fora da instalação, o que é desejável (Abreu \& Abreu, 2000). No entanto, a ventilação natural durante o inverno, nem sempre poderá garantir que as condições climatéricas proporcionem uma adequada movimentação do ar. Assim, a aquisição de ventilação mecânica ou forçada, parece ser a solução mais adequada, visto permitir a filtragem, distribuição uniforme e suficiente do ar no aviário e ser independente das condições atmosféricas (Abreu \& Abreu, 2000). Para além do compartimento nos aviários, é sugerido que, para a recuperação térmica do trabalhador, deva existir outra zona comum a todos os trabalhadores, onde estes possam repousar após algum tempo de trabalho no exterior, ou no interior. Sugere-se, portanto, que haja uma organização do trabalho, isto é, que sejam primeiramente realizadas todas as atividades que envolvam exposição ao calor ou ao frio, no sentido de existir aplicabilidade das medidas corretivas individuais propostas. Esta organização do trabalho, não pretende aumentar o tempo de exposição, mas sim promover a saúde e segurança do trabalhador, pelo que deverão existir intervalos de recuperação térmica durante as tarefas executadas.

Salienta-se, para promover a saúde dos trabalhadores, a importância da ingestão de água ao longo do dia, bem como de uma alimentação equilibrada e evitar o consumo de bebidas alcoólicas nas noites que antecedem uma jornada de trabalho (o álcool ingerido faz com que aumente ainda mais a necessidade de ingestão de água), usar roupas limpas na execução das tarefas laborais (as roupas sujas são menos ventiladas em função do suor, pó e outros produtos presentes) (Coelho, 2018; Silva \& Almeida, 2010).

Durante a elaboração do estudo, foram encontradas algumas limitações, tais como o tamanho reduzido da amostra, tanto no que se refere ao número de aviários avaliados, como no que se refere ao número de trabalhadores.

\section{CONCLUSÃO}

Após a realização deste estudo e do que se observou nos aviários, parece existir valorização do bem-estar animal, mas não da segurança e saúde dos trabalhadores.

É indiscutível o desconforto térmico que se verifica na maior parte das exposições ao calor e ao frio, pela avaliação do índice PMV-PPD. Apenas se poderá dizer que existe algum conforto térmico para o trabalhador, nas tarefas realizadas dentro dos aviários para frangos com 85 dias de idade, atendendo ao facto de todas as medições realizadas no interior dos aviários, para frangos com 8 e 35 dias de idade, revelarem sensações térmicas inadequadas. Foi detetada como situação mais crítica, em termos de desconforto térmico, a 
exposição no interior dos aviários destinados aos frangos com 8 dias, revelando assim a relação entre o índice de conforto térmico e a fase de desenvolvimento do frango.

Na solução de um problema de saúde ocupacional devem ser consideradas, primeiramente, as medidas relativas ao ambiente que geralmente são complementadas pelas medidas relativas ao trabalhador, assim sendo foram sugeridas medidas construtivas ao nível da ventilação, da existência de uma zona de recuperação térmica e ainda outra zona para descanso do pessoal, após a exposição ocupacional ao frio ou ao calor. Quanto às medidas individuais, foi aconselhado o uso de vestuário adequado consoante o local das tarefas - interior ou exterior dos aviários. Contudo, quando falamos sobre equipamentos de proteção individual, é sempre importante lembrar que não basta fornecê-lo, é necessário orientar e informar/formar sobre o seu modo de utilização.

Torna-se igualmente útil a realização de estudos semelhantes em diferentes áreas geográficas do país, bem como em estações do ano distintas, de modo a comparar as variações dos parâmetros avaliados no tempo e no espaço, pois espera-se que os resultados sejam diferentes de região para região e de época do ano para época do ano.

Além dos estudos que permitam avaliar o conforto térmico dos trabalhadores no ambiente interior e exterior dos locais e postos de trabalho, é essencial a sensibilização dos trabalhadores para a problemática da influência dos fatores individuais e ambientais no conforto térmico, nomeadamente nos comportamentos corretos a adotar.

\section{REFERÊNCIAS BIBLIOGRÁFICAS}

Abreu, P., \& Abreu, V. (2000). Ventilação na avicultura de corte. Concórdia, Brasil: Embrapa.

Almeida, H. (2010). Análise do conforto térmico de edifícios utilizando as abordagens analítica a adaptativa (Dissertação de Mestrado não publicada). Instituto Superior Técnico, Universidade de Lisboa, Lisboa, Portugal.

Fanger, P. O. (1970). Thermal Comfort: analysis and applications in environmental engineering. Copenhagen: Danish Technical Press.

Fernandes, F. C., \& Furlaneto, A. (2004). Riscos Biológicos em Aviários. Revista Brasileira de Medicina no Trabalho, 2(2), 140-152.

Hudie, L. A. (2016). Ergonomics of the thermal environment Determination of metabolic rate. Basis for the edition of the standard ISO 8996, 1-14. Retirado de https://www.researchgate.net/profile/Lesley-AnneHudie/publication/306013139 Ergonomics of the th ermal environment Determination of metabolic ra te/links/57aa26fc08ae3765c3b4a2b6/Ergonomics-ofthe-thermal-environment-Determination-ofmetabolic-rate.pdf

ISO 7730:2005. (2005). ISO 7730:2005 - Ergonomics of the thermal environment - Analytical determination and interpretation of thermal comfort using calculation of the PMV and PPD indices and local thermal comfort criteria. International Organization for Standardisation.

Lei n.o 3/2014, de 28 de janeiro de 2014, Diário da República n.o 19/2014, Série I, Assembleia da República, Lisboa, Portugal.

Miguel, A. (2014). Manual de Higiene e Segurança no Trabalho (13.a ed.). Porto: Porto Editora.

Minette, L., Silva, E., Souza, A., \& Silva, K. (2007). Evaluation of noise, light and heat levels of forest harvesting machines. Revista Brasileira de Engenharia Agrícola e Ambiental, 11(6), 664-667.

Oliveira, A. (2008). Avaliação da Incerteza na Determinação dos Índices de Conforto Térmico PMV e PPD (Tese de Mestrado não publicada). Faculdade de Ciências e Tecnologia, Universidade de Coimbra, Coimbra, Portugal.

Portaria n.o 702/80 de 22 de setembro (1980). Diário da República n.o 219/1980. I Série. Ministérios do 
Trabalho, dos Assuntos Sociais, da Agricultura e Pescas e da Indústria e Energia, Lisboa, Portugal.

Portaria n.o 53/71 de 03 de fevereiro (1971). Diário da República no 28/1971. I Série. Ministérios da Economia, das Corporações e Previdência Social e da Saúde e Assistência, Lisboa, Portugal.

Sá, R. (1999). Introdução ao "stress" térmico em ambientes quentes. Tecnometal, 124

Sanguessuga, M. (Abril de 2012). Síndroma dos Edifícios Doentes: Estudo da qualidade do ar interior e despiste da eventual existência de SED entre a população do edifício " $E$ " de um estabelecimento de ensino superior (Dissertação de Mestrado). Escola Superior de Tecnologia da Saúde de Lisboa, Instituto Politécnico de Lisboa, Lisboa, Portugal.

Silva, P. (2013). Estudo do Conforto Térmico numa Lavandaria/Engomadoria. Setúbal: Instituto Politécnico de Setúbal.
Silva, T., \& Almeida, V. (2010). Influência do Calor sobre a Saúde e desempenho dos trabalhadores. Simpósio Maringarense de Engenharia de Produção.

Sousa, J., Silva, C., Pacheco, E., Moura, M., Araújo, M., \& Fabela, S. (2005). Acidentes de Trabalho e Doenças Profissionais em Portugal : Risco Profissional - Factores e Desafios. Gaia: Estudos CPRG

Spillere, J., \& Furtado, T. (2007). Estresse ocupacional causado pelo calor (Mongrafia para obtenção de título de especialista), Universidade do Extrema Sul Catarinense, Criciúma, Brasil.

Talaia, M. (2013). Riscos no local de trabalho ambiente térmico quente. 555-567. Retirado de https://www.uc.pt/fluc/depgeo/Publicacoes/livro ho menagem FRebelo/555 567

Vergara, L. (2001). Análise das condições de conforto térmico de trabalhadores da unidade de terapia intensiva do Hospital Universitário de Florianópolis. Florianópolis: Universidade Federal de Santa Catarina 